\title{
OBJECTIVELY MEASURED SCHOOL-BASED PHYSICAL ACTIVITY INTERVENTIONS FOR 6-12-YEAR-OLD CHILDREN IN 2009-2014: A SYSTEMATIC REVIEW
}

\author{
Eva-Maria Riso, Merike Kull, Aave Hannus \\ Research Laboratory of Behavioural Physical Activity, \\ Faculty of Exercise and Sport Sciences, University of Tartu, Tartu, Estonia
}

\begin{abstract}
Physical inactivity of children and youth is a growing problem all over the world. The promotion of physical activity (PA) is an essential strategy to improve the physical and mental health of students. The school setting is a good environment for population-based PA interventions. The purpose of the present study was to determine whether school-based PA interventions have influence on the PA level of children aged 6- to 12 years and to describe the main components of PA interventions. A literature selection was carried out including original articles describing school-based PA interventions for 6- to 12 years old children, objectively measured by accelerometers or pedometers, published 2009-2014. Seventeen relevant trials of sufficient quality performed in 10 different countries were identified. The analyses of articles revealed that active recess was the most wide-spread component of PA interventions, followed by activity breaks in lessons and PE lessons. Increase of PA was achieved in 16 analyzed studies, but multicomponent interventions and interventions, containing mandatory elements, seemed to be most effective.
\end{abstract}

Keywords: physical activity, school-based intervention, active recess, activity break, additional PE lesson

\section{INTRODUCTION}

Insufficient physical activity (PA) is a global health problem [34]. The promotion of PA is an essential public health strategy to improve the health 
of individuals and populations [33]. According to the Health Behaviour in School-aged Children (HBSC) study, less than two-thirds of all young people meet the current guidelines of recommended PA [32]. There is ample of evidence that participating in PA can lead to a variety of benefits for children and adolescents: better physical health [5], more positive physical self-concept and self-esteem [6], and achievement of higher academic results [27].

The school setting is an ideal environment for PA intervention. No other institution has as much influence on children in the first two decades of life [28]. PA at schools has also been demonstrated to be indirectly linked with academic achievement, better classroom behavior, self-esteem and engagement in school [20,30]. Schools have potential to become the important element in a community that ensures students to participate in the recommended amount of time engaged in PA [16, 25]. Schools provide benefits for students from all risk groups [13], particularly for those with limited or no access to play areas [21]. Leading organizations recommend that schools implement policies that require daily physical education (PE); elementary school recess; and PA before, during, and after school [7, 25]. Although most schools require PE as a part of their curriculum, PE classes may occur infrequently and children are often relatively inactive in them [25]. It is thus essential to promote PA throughout the school day during classes, lunch times, and recess, and to develop strategies to promote more efficient use of PE class time [7].

The age between 6- to 12 years is critical in forming healthy life-style behaviour and PA habits. Previous studies [17] have shown that sufficient PA during first grades and increased PA at school ensures more active participation in sports activities outside of school among teenagers. As school-aged children may have many barriers that disturb participation in PA outside of the school setting, it is necessary to understand the extent to which schoolbased PA interventions are effective in increasing activity level. Objectively measured outcomes are very important to evaluate the effect of PA intervention. Using accelerometers or pedometers enables researchers to estimate the influence of intervention on the PA level better than applying questionnaires, especially among younger children.

The purpose of present study is to determine whether school-based PA interventions have influence on the PA level of children aged 6-12 years and to describe the effective components of PA interventions. 


\section{MATERIALS AND METHODS}

\section{Selection of materials}

A literature selection was carried out in June 2014. A structured electronic literature search was conducted with standards set forth in the Preferred Reporting Items for Systematic Reviews and Meta-analyses ${ }^{\star}($ PRISMA) statement [22]. The following electronic EBSCO databases were used: Medline, ERIC, PsycInfo, SportDiscus, Teacher Reference Center, using a time frame from January 2009 to June 2014. Following search strings were used: schoolbased physical activity intervention AND physical activity intervention and physical activity OR physical activity programme AND accelerometer. These strings were limited to English language.

The base of this paper is the collection of recent original articles published 2009 and later.

Inclusion criteria were: (1) school-based intervention to increase PA; (2) participants were children between the ages 6- and 12 years, corresponding to the mandatory school age, while adolescents were 13 year or older and were excluded; (3) objectively measured outcomes - PA measured as an outcome at baseline and at least one follow-up, using accelerometer or pedometer; (4) controlled trials or randomized controlled trials of interventions that aimed to increase PA; (5) statistical analyses of the PA outcome reported; and (6) only original articles were included.

Only full-text original articles published in peer-reviewed academic journals were considered. Review articles and studies in children with specific diseases, also studies applying special exercise programmes for obese or preschool children and adolescents were excluded. Flowchart of study selection is presented on Figure 1. After exclusion of non-relevant studies, the full text of each included study was read and analysed by researchers. 


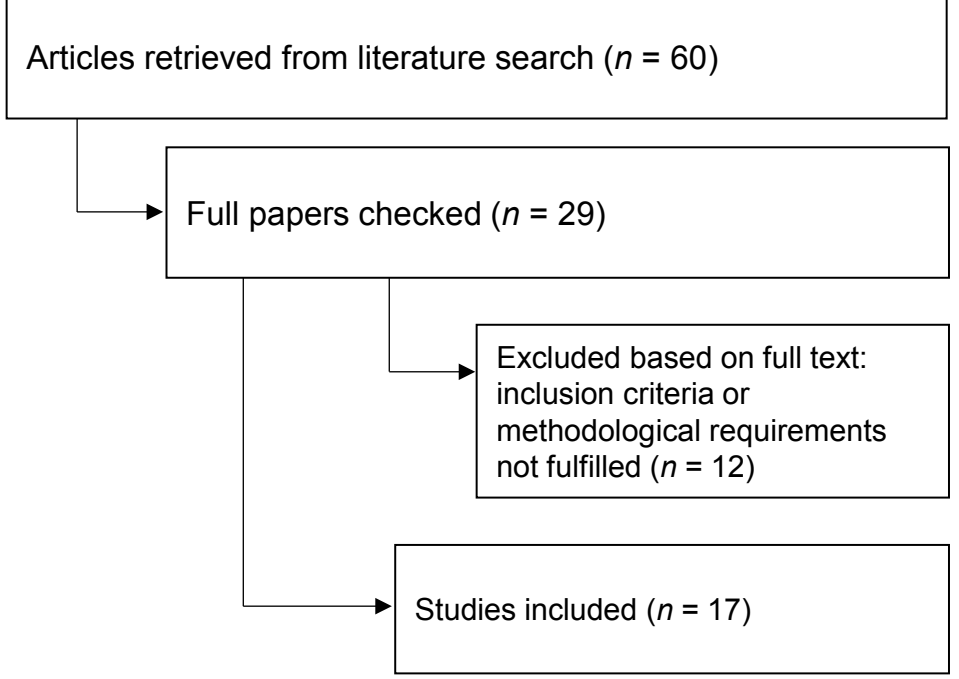

Figure 1. Flowchart of study selection.

\section{RESULTS}

Seventeen relevant trials of sufficient quality were identified. All selected studies differed in their duration, number of participants and the content of intervention. There were no two studies with similar programme. The main characteristics of school-based PA intervention trials: authors, country and duration of intervention, number of students, type and content of intervention programme, possible effect on PA level, changes made in school area or additional learning materials used, engagement of parents and family members, guidance of the intervention, mandatory or voluntary character of the trial are depicted in Table 1. 


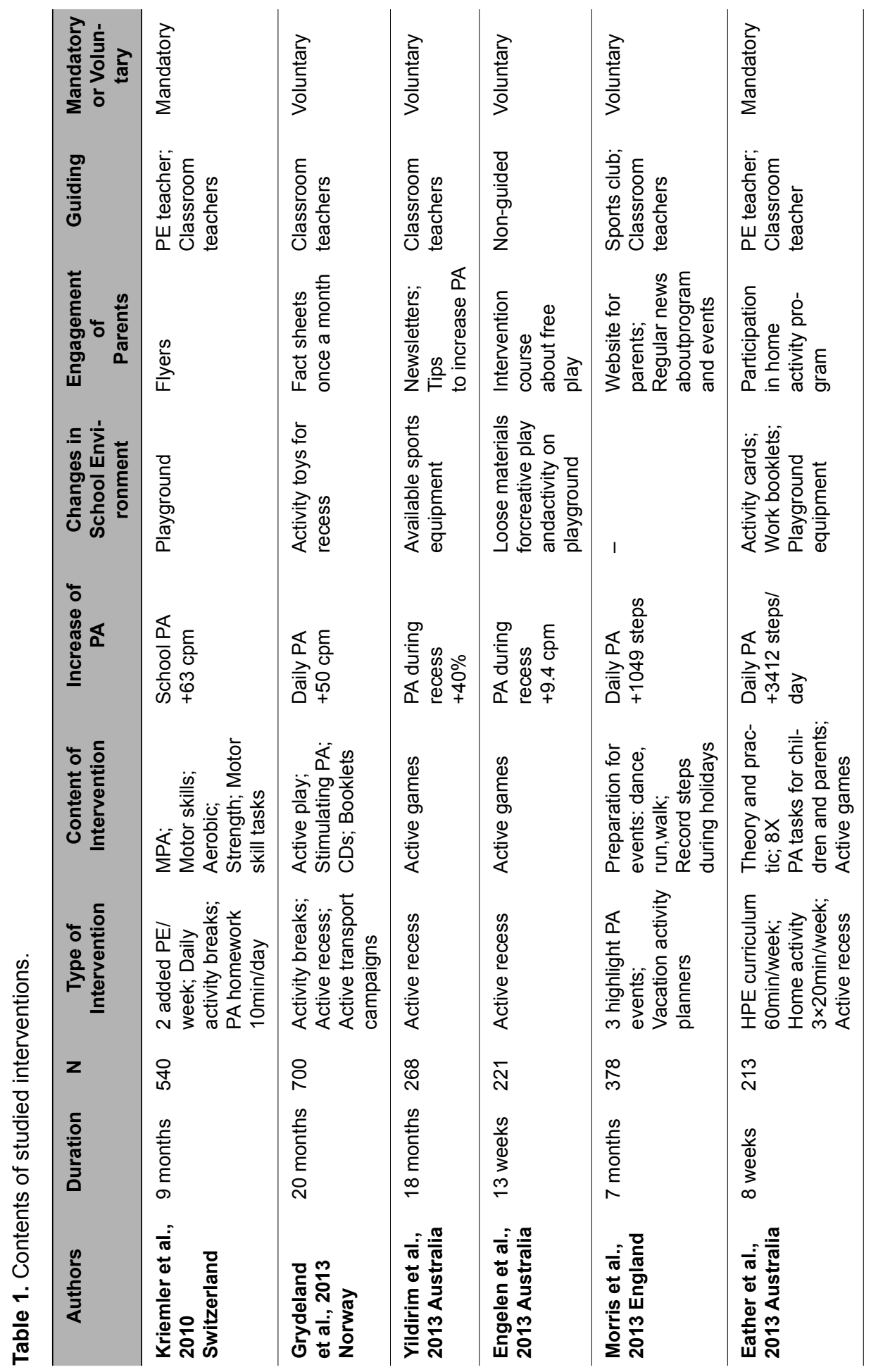




\begin{tabular}{|c|c|c|c|c|c|}
\hline 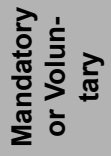 & $\begin{array}{l}\frac{7}{0} \\
\frac{0}{\pi} \\
\frac{\pi}{0} \\
\frac{10}{10} \\
\sum\end{array}$ & $\begin{array}{l}\frac{2}{0} \\
\frac{0}{\pi} \\
\frac{\pi}{0} \\
\frac{\pi}{\pi} \\
\frac{\pi}{2}\end{array}$ & 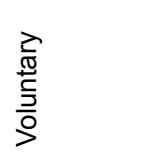 & 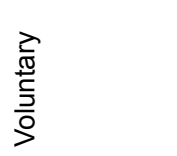 & $\begin{array}{l}\frac{1}{0} \\
\frac{0}{\pi} \\
\frac{0}{0} \\
\frac{\pi}{2} \\
\sum\end{array}$ \\
\hline & 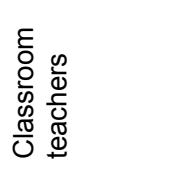 & 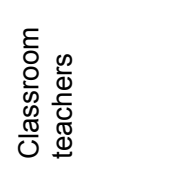 & $\begin{array}{l}\frac{8}{d} \\
\frac{0}{0} \\
\overline{0} \\
\frac{1}{0} \\
z \\
z\end{array}$ & 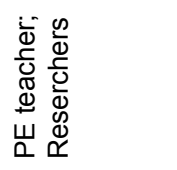 & 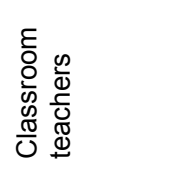 \\
\hline 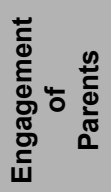 & 1 & & 1 & 1 & , \\
\hline 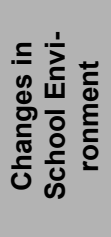 & 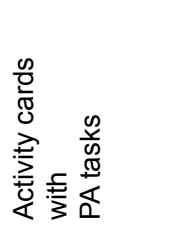 & 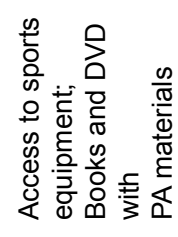 & 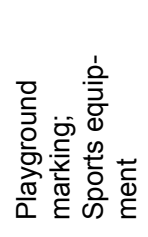 & 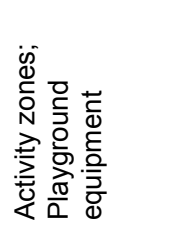 & $\begin{array}{l}\sum_{0}^{\infty} \\
\sum_{i 0}^{00} \\
0 \\
0 \\
0\end{array}$ \\
\hline 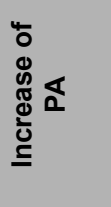 & 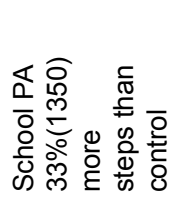 & 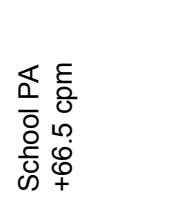 & 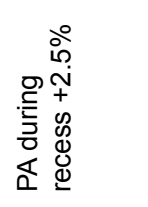 & 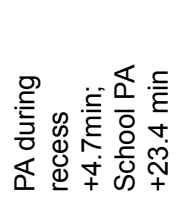 & 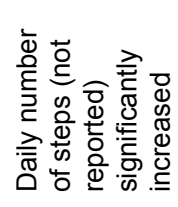 \\
\hline 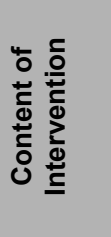 & 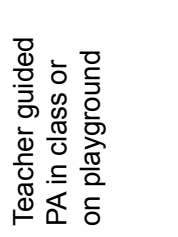 & 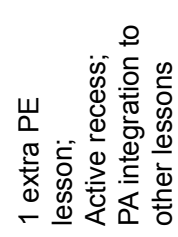 & 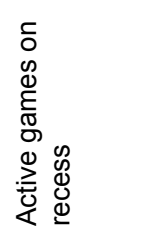 & 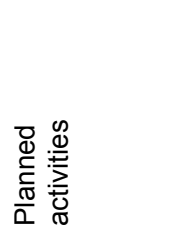 & 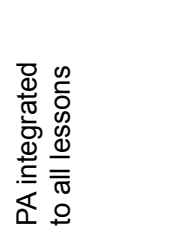 \\
\hline 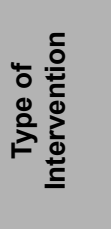 & 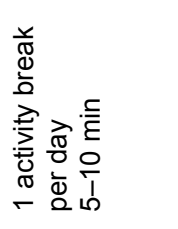 & 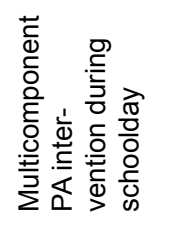 & 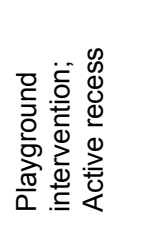 & 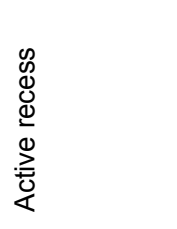 & 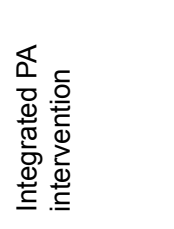 \\
\hline$z$ & $\stackrel{8}{\circ}$ & $\stackrel{\mathscr{N}}{N}$ & ঙ্ণি & ळ & 용 \\
\hline סू & 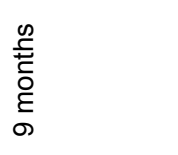 & 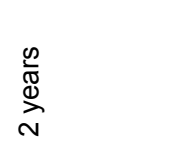 & 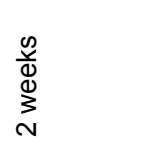 & 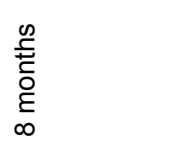 & 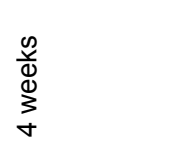 \\
\hline $\begin{array}{l}\frac{n}{2} \\
\frac{2}{5} \\
\frac{5}{2}\end{array}$ & 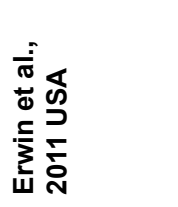 & 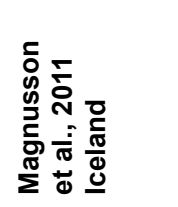 & 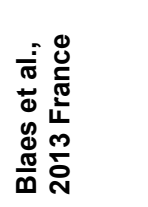 & 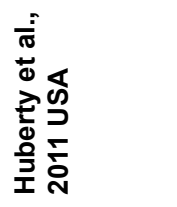 & 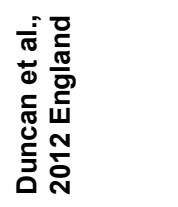 \\
\hline
\end{tabular}




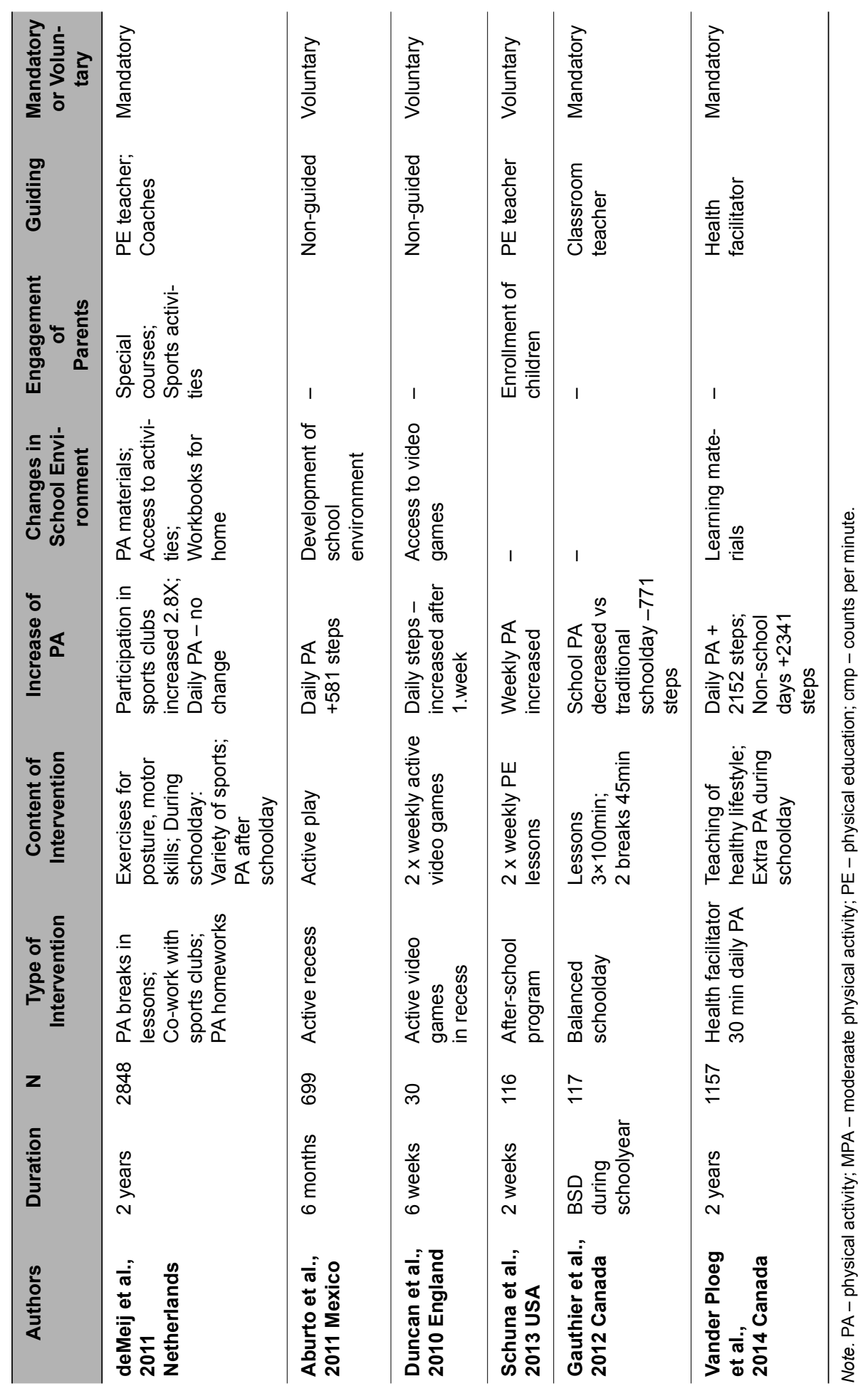


Variety of countries were represented in the reviewed studies. Three trials were performed in USA $[12,15,26]$, three in UK $[8,9,23]$, three in Australia $[10,11,35]$, two in Canada $[13,31]$ and one each in Switzerland [18], Norway [14], Netherlands [4], Mexico [1], Iceland [19], and France [3]. The study sample size at baseline was from 30 [9] to 2848 [4] students. The average sample size was 483 students. The participant age ranged from 6- to 12 years. The duration of intervention ranged from 2 weeks [3] to 2 years [4, 19, 31]. 10 trials lasted more than 6 months. A control group was used in all studies. A causal relationship between an intervention and its outcomes is best shown using the comparison of a control and intervention group.

Eight intervention programmes had mandatory components $[4,8,10$, $12,13,18,19,31]$ and nine programmes $[1,3,9,11,14,15,23,26,35]$ were voluntary. An intervention programme component was defined as mandatory if it was an integral part of the school programme in which the participants - neither students nor teachers - had a possibility of withdrawal. The mandatory component was usually an extra PE or health promotion education (HPE) lesson, added to the curriculum in three trials $[10,12,18]$ and in five trials, it was a the part of PA integration to other lessons or schoolday activities $[1,4,8,12,31]$. In most programmes the students and their parents had to sign the consent form to confirm their participation in the trial.

Intervention types and contents are summarized in Table 1 . The most widely used type of PA intervention in analysed studies was active recess 8 times $[1,3,9,10,11,14,19,35]$, followed by activity break in academic lessons $[4,12,14,18]$ and additional PE lessons 4 times [18, 19, 26, 31]. PA homework or vacation activity planners were applied in 4 studies $[4,10,18$, 23]. In one study the active transport campaign was used [14].

Studies differed in the number of PA increasing components included to the intervention. In five studies 3 different PA components were used $[4,10$, $14,18,26]$. Four of them had at least one mandatory component $[4,10,18$, 26]. The combinations of different PA elements were: 2 additional PE lessons + daily activity breaks + PA homework [18]; daily activity breaks + active recess + active school transport campaign [14]; HPE added to curriculum $60 \mathrm{~min} /$ week for 8 weeks + PA homework + active recess [10]; 1 additional PE lesson + active recess + PA integration to other lessons [19]; PA breaks in other lessons + PA homeworks + co-work with sports clubs [4].

PA homework consisted of PA tasks for children and parents $3 \times 20 \mathrm{~min} /$ week [10]; aerobic, strength and motor skill tasks 10 min daily [18] and activity with PA workbook tasks [10]. In one study the students were provided with holiday activity planners [23]. 
Additional PE lessons were carried out by PE teachers and a special programme, created by researchers, was used $[4,18]$.

Two studies included 2 components of PA intervention. In one of them three highlight PA events were divided on the schoolyear and the students trained for them. In this study, the students were also provided with special vacation activity planners for holidays to keep the recommended PA level. The students wear pedometers during holiday week and tried to meet the recommended number of steps [23]. In the other 2-component study, the school had hired a health facilitator whose task was to promote healthy lifestyle among the students and daily $30 \mathrm{~min}$ PA was added to curriculum [31].

Ten studies $[1,3,8,9,11,12,13,15,26,35]$ had one component to influence the physical activity of children. Active recess on school playground was applied in five one-component intervention study $[1,3,11,15,35]$, PA integration to academic lessons in one another study [8], daily activity break in one study [12], active video games twice a week [9] and additional after-school PE lessons 2 times per week [26] were used both in one study. To compare the PA of student in traditional school and in case of changed timetable, the balanced schoolday was used in one study [13].

Objectively measured PA was one of the main inclusion criteria in this overview. Accelerometers or pedometers were used in all studies. Significant increase of PA was reported in all interventions except one [13], in which the effect of balanced schoolday on the PA of students was investigated. During the balanced schoolday with longer lessons $3 \times 100 \mathrm{~min}$ and two 45 min breaks between them, the number of steps per schoolday decreased. The increase of PA during schoolday was achieved in four studies $[12,15$, $18,19]$. PA during recess increased in four studies $[3,11,15,35]$. Seven interventions had positive effect on daily or overall PA $[1,8-10,14,23,31]$. Increase of PA per week was reported in one study [26]. In one study [4] the increased participation in sports clubs was demonstrated after intervention programme. The increased PA during recess or activity breaks had simultanous effect on daily PA $[1,9,10,14,15,18]$.

The increase of PA was expressed using different methods. The increase of PA during active recess was shown as the augment of counts per minute cpm $(+9.4 \mathrm{cpm})$, measured by accelerometer, in one study [11]. Comparison of recess PA with baseline level was applied twice [3,35], the recess PA was $40 \%$ and $2.5 \%$ higher respectively. In one study [15] the absolute PA time was 4.7 min longer as compared with baseline level. PA increase during schoolday was registered by using amount of cpm in two studies [18, 19] , $+63 \mathrm{cpm}$ and $+66.5 \mathrm{cpm}$ accordingly. In one study [12] the increase of 
PA at school was achieved by additional 1350 steps which was $33 \%$ more than baseline level. In study [15] the PA time at school increased $23.4 \mathrm{~min}$ as compared to baseline level. The increase of daily PA was most often expressed by measuring the number of additional steps [1, 8-10, 23, 31]. In two studies $[8,9]$ the amount of steps was not given, although the significant change in PA was reported. The biggest number of additional daily steps was +3412 and $+2152[10,31]$. In one study the increase in cpm was demonstrated for daily PA [18]. In one study [4] the 2.8 times increase in participation of sports clubs was found, but the daily PA did not change at the same time. One study [14] has shown the significantly increased time for MVPA (+22 min/ per session twice a week).

Different time intervals have been used in these studies: overall PA was measured in one study [14], PA during schoolday in two studies [18, 19] and PA during recess in one study [11]. In three studies the increase of PA duration was measured $[3,15,35]$. In one study [4] the participation in sports clubs increased 2.8 times, although the daily PA did not change.

The interventions, including mandatory elements, seemed to be most effective in increasing PA [8-12, 18, 19, 31], although also the voluntary interventions had significant effect on PA level.

In most studies the schools had to develop the school environment [1, $3,18]$ or to provide students with sports equipment and activity toys $[3,4$, $10,11,14,15,19,35]$. Video game was used in one study [9] and GPS with specific maps also in one study [8]. Printed materials: learning instructions, activity cards, workbooks were used in five studies $[4,10,12,19,31]$ and DVD with PA materials in one study [19].

The engagement of parents was a part of eight interventions $[4,10,11$, $14,18,23,26,35]$. Co-work with parents and family included flyers, newsletters, website $[14,18,23,35]$, participation in intervention course $[4,11]$ or home PA programme [10], enrollment of children [26].

Most of interventions were guided: six studies by only classroom teacher $[8,12-14,19,35]$, one study by PE teacher [4], two studies by classroom teacher + PE teacher $[10,18]$, two studies by PE or classroom teachers together with sportsclub coaches $[4,23]$. Health facilitator guided one study [31] and PE teacher with researchers also in one study [15]. 


\section{DISCUSSION}

The purpose of this review was to give an overview about the effectiveness of the objectively measured school-based physical activity interventions on the PA level in school attending children aged 6 to 12 years. Seventeen studies met the criteria to be included to the review. The number of students in different studies varied between studies from only 30 to even 2848 students whereas the mean number of participants was 483 . The longest interventions lasted 2 years and had the biggest sample size. In two studies with smallest number of participants additional special technical equipment was used - GPS map or video game. In smaller groups, there is a good possibility to increase the PA level during schoolday and to match the interest of children to technology at the same time. The most popular intervention components were active recess and activity breaks, used widely both in multi-component and single-component studies. The length of recess was usually $25-30 \mathrm{~min}$ in analysed interventions, which is in good accordance with previous reviews, not included to this paper [2, 24]. As a tradiotional schoolday enables mainly activities on sedentary level, beyond PE, recess or activity break may be one of the only times during the school day that children have an opportunity to be active and accumulate some of the necessary minutes to meet recommended guidelines of 60 minutes of PA per day [29]. It is important to emphasize that the children were more physically active not only during recess, they were also more active during the school day or whole day. As the result of this overview we can conclude that recess activity is an important element to add PA into students' daily life.

Mandatory components in PA interventions are considered to be effective to increase the PA level during a schoolday. In our review, six studies including mandatory elements had a significant effect to the increase of PA. In studies included in our overview, additional PE or HPE lesson or PA integrated to all lessons influenced positively the PA level of students during schooldays.

Concerning school environment, in most studies, except two the changes in school environment or access to sports equipment were organized. The results of this review show that stimulating environment helps to increase the PA of children during schooldays. Moreover, PA homework was applied in several studies with the aim to increase PA outside the school.

The cooperation with parents and families was not the main task of school-based interventions, but, to some extent, the co-work with parents was applied more or less. As the engagement of parents was one element of multicomponent programmes its specific effectiveness was not measured. 
However, previous researches have shown that the instruction of parents remains a necessary part of school-based interventions, because their attitude has a great influence on the lifestyle and habits of health behaviour in children [7].

Our study shows that most interventions were guided by classroom teacher. Obviously the engagement of PE teachers, coaches or health facilitator enables better supervision and social support of children activity during PE lesson and active recess. Although non-guided activities included mainly free play during recess, they have an important role for children to develop the skills of self-dependent activities and promote social skills [11].

Significant increase of PA as a result of intervention was reported in all included studies except one. Dependent from the intervention programme PA increased during recess, schoolday or whole day. Although the interventions had different content, took place in different countries and different measurement systems were used, the results confirmed the positive effect on PA level of children. As mentioned earlier, augment of PA in school may have further effect on PA outside of school.

One limitatation of our study appeared in comparison of effectiveness of included interventions. Although accelerometers or pedometers were used in all interventions and the statistical analyzes of outcomes were reported, it is difficult to compare the different data, as the increase of PA was expressed using different methods. There is no existing unitary method to express the results of PA interventions. The most frequent outcome measure of PA level was expressed as number of steps per day or schoolday. Pedometers were used mostly in analyzed studies but those give information only about the steps done in certain time interval, but the intensity of PA remains unknown. Despite of this limitation, pedometer is an unexpensive instrument for estimating PA level among children. Only in four studies the increase of amount of counts per minute, using accelerometer, was registered. Accelerometers have acceptable reliability and validity for quantifying PA among children $[7,29]$. As the intervention design and estimated time intervals are variable between different studies, the comparison is complicated. Even by using the objective measuring instruments - accelerometers or pedometers, authors present their results differently. The absolute amount of PA is often not given and relative comparison with baseline level is reported instead of that. The main task of school-based interventions is also different - whether increase the daily PA, PA during schoolday or recess.

Summarizing the results of this review we can conclude that effective school-based intervention models include additional PE lessons, active 
recess, activity breaks and changes in school environments. In numerous school-based interventions the increase of PA level has been achieved. Objective comparability of the changes in PA level measurements helps to understand and explain the effect of population-based interventions and to create the most suitable intervention programmes to increase the PA level in every age group.

\section{ACKNOWLEDGEMENTS}

This study was supported by the foundation for science promotion of Tartu University.

\section{REFERENCES}

1. Aburto NJ, Fulton JE, Safdie M, Duque T, Bonvecchio A, Rivera JA. (2011) Effect of a School-Based Intervention on Physical Activity: Cluster-Randomized Trial. Med Sci Sports Exerc, 43: 1898-1906

2. Bassett DR, Fitzhugh EE, Heath GW. (2013) Estimated energy expenditures for school-based policies and active living. Am J Prev Med, 44: 108-113

3. Blaes A, Ridgers ND, Aucouturier J, Van Praagh E, Berthoin S, Baquet G. (2013) Effects of a playground marking intervention on school recess physical activity in French children. Prevent Med, 57: 580-584

4. de Meij JSB, Chinapaw MJM, van Stralen MM, van der Wal MF, van Dieren L, van Mechelen W. (2011) Effectiveness of JUMP-in, a Dutch primary school-based community intervention aimed at the promotion of physical activity. Br J Sports Med, 45: 1052-1057

5. Demetriou Y, Höner O. (2012) Physical Activity interventions in the school setting: a systematic review. Psychol Sport Exerc, 13: 186-196

6. Dishman RK, Hales DP, Pfeiffer KA. (2006) Physical self-concept and self-esteem mediate cross-sectional relations of physical activity and sport participation with depression symptoms among adolescent girls. Health Psychol, 25: 396-407

7. Dobbins M, Husson H, DeCorby K, LaRocca RL. (2013) School-based physical activity programs for promoting physical activity and fitness in children and adolescents aged 6 to 18. Cochrane Database Syst Rev, doi: 10.1002/14651858.CD007651 pub2

8. Duncan M, Birch S, Woodfield L. (2012) Efficacy of an integrated school curriculum pedometer intervention to enhance physical activity and to reduce weight status in children. Eur Phys Education Rev, 18: 396-407 
9. Duncan MJ, Staples V. (2010) The impact of a school-based active video game play intervention on children's physical activity during recess. Hum Mov, 11: 95-99

10. Eather N, Morgan PJ, Lubans DR. (2013) Improving the fitness and physical activity levels of primary school children: Results of the Fit-4-Fun group randomized controlled trial. Prevent Med, 56: 12-19

11. Engelen L, Bundy AC, Naughton G, Simpson JM, Bauman A, Ragen J, Baur L, Wyver S, Tranter P, Niehues A, Schiller W, Perry G, Jessup G, van der Ploeg HP. (2013) Increasing physical activity in young primary school children - it's child's play: A cluster randomised controlled trial. Prev Med, 56: 319-325

12. Erwin HE, Beighle A, Morgan CF, Noland M. (2011) Effect of a Low-Cost, Teacher-Directed Classroom Intervention on Elementary Students' Physical Activity. J Sch Health, 81: 455-461

13. Gauthier AP, Laurence M, Thirkill L, Dorman SC. (2012) Examining School-Based Pedometer Step counts Among Children in Grades 3 to 6 Using Different Timetables. J Sch Health, 82: 311-317

14. Grydeland M, Bergh IH, Bjelland M, Lien N, Andersen LF, Ommundsen Y, Klepp K-I, Anderssen SA. (2013) Intervention effects on physical activity: the HEIA study - a cluster randomized controled trial. Int J Behav Nutr Phys Act, 10: 17

15. Huberty JL, Siahpush M, Beighle A, Fuhrmeister E, Silva P, Welk G. (2011) Ready for Recess: a Pilot study to Increase Physical Activity in elementary School Children. J Sch Health, 81: 251-257

16. Koplan JP, Liverman CT, Krakk VI, eds. (2005) Preventing Childhood Obesity: Health in the Balance. Washington, D.C.: National Academic Press.

17. Kriemler S, Meyer U, Martin E, van Sluijs EMF, Andersen LB, Martin BW. (2011) Effect of School-based interventions on physical activity and fitness in children and adolescents: a review of reviews and systematic update. $\mathrm{Br}$ J Sports Med, 45: 923-930

18. Kriemler S, Zahner L, Schindler C, Meyer U, Hartmann T, Hebestreit H, Bruner-LaRocca HP, van Mechelen W, Puder JJ. (2010) Effect of schoolbased physical activity programme (KISS) on fitness and adiposity in primary schoolchildren: cluster randomised controlled trial. BMJ, 340: c785

19. Magnusson KT, Sigurgeirsson I, Sveinsson T, Johannsson E. (2011) Assessment of a two-year school-based physical activity intervention among 7-9-year-old children. Int J Behav Nutr Phys Activity, 8: 138

20. Mahar MT, Murphy SK, Rowe DA, Golden J, Shields AT, Raedeke TD. (2006) Effects of a classroom-based program on physical activity and ontask behaviour. Med Sci Sports Exerc, 38: 2086-94

21. McKenzie TL, Nader PR, Strikmiller PK, Yang M, Stone EJ, Perry CL. (1996) School physical education: effect of the Child and Adolescent Trial for Cardiovascular Health. Prevent Med, 25: 423-31 
22. Moher D, Liberati A, Tetzlaff J. (2009) Preferred reporting items for systematic reviews and meta-analyses: the PRISMA statement. J Clin Epidemiol, 62: $1006-12$

23. Morris JG, Gorely T, Sedgwick MJ, Nevill A, Nevill ME. (2013) Effect of the Great Activity Programme on healthy lifestyle behaviours in 7-11 year olds. J Sports Sci, 31: 1280-1293

24. Parrish A.-M, Okely AD, Stanley RM, Ridgers ND. (2013) The Effect of School Recess Interventions on Physical Activity. A systematic review. Sports Med, 43: 287-299

25. Pate RR, Davis MG, Robinson TN, Stone EJ, Mc Kenzie TL, Young JC. (2006) Collaboration with the councils on cardiovascular disease in the young and on nutrition, physical activity, and metabolism (Physical Activity Committee) in schools: a scientific statement from the American Heart Association council promoting physical activity in children and youth: a leadership role for cardiovascular nursing. Circulation, 114: 1214-1224

26. Schuna JM, Lauersdorf RL, Behrens TK, Ligouri G, Liebert ML. (2013) An Objective Assessment of Chuildren's Physical Activity During the Keep It Moving! After-School Program. J Sch Health, 83: 105-111

27. Singh A, Uijtdewilligen L, Twisk JWR, van Mechelen W, Chinapaw MJM. (2012) Physical activity and perfomance at school: a systematic review of the literature including a methodological quality assessment. Arc Pediatr Adolesc Med, 166: 49-55

28. Story M, Nanney MS, Schwartz MB. (2009) Schools and obesity prevention: creating school environments and policies to promote healthy eating and physical activity. Milbank Q, 87 (1): 71-100

29. Strong WB, Malina RM, Blimkie CJ. (2005) Evidence-based physical activity for school-age youth. J Pediatr, 146: 732-737

30. Trudeau F, Shepard RJ. (2008) Physical education, school physical activity, school sports and academic perfomance. Int J Behav Nutr Phys Activity, 5: 10

31. Vander Ploeg KA, McGavock, Maximova K, Veugelers PJ. (2014) Schoolbased Health Promotion and Physical Activity During and after School Hours. Pediatrics, 133: e371-e379

32. WHO (2004b) Young people's health in context. Health behaviour in school-aged children (HBSC) study: international report from the 2001/2002 survey. WHO. Health Policy for Children and Adolescents, No. 4. Copenhagen, Edinburgh, 3 June 2004, 2004; Vol. Health Policy for Children and Adolescents, No. 4

33. WHO. (2004a) Global strategy on Diet, Physical Activity and Health. http://www.who.int/healthinfo/global_burden_disease/GlobalHealthRisks_ report_full.pdf

34. WHO (2009). Global health risks: mortality and burden of disease attributable to selected major risks (online). www.who.int/dietphysicalactivity/ strategy/eb11344/en/. 
35. Yildirim M, Arundell L, Cerin E, Carson V, Brown H, Crawford D, Hesketh KD, Ridgers ND, TE Velde, Chinapaw MMJ, Salmon J. (2013) What helps children to move more at school recess and lunchtime? Mid-intervention results from Transform-Us! Cluster-randomized controlled trial. Br J Sports Med, 48: 271-277

\section{Correspondence to:}

Eva-Maria Riso

Research Laboratory of Behavioural Physical Activity

Faculty of Exercise and Sports Sciences

University of Tartu

5 Jakobi Str, Tartu 51014, Estonia

Telephone: +3727376033

E-mail: eva-maria.riso@ut.ee 